\title{
Aleitamento materno: uma contribuição científica para a prática do profissional de saúde
}

\author{
Breastfeeding: a scientific contribution to the practice of health care providers
}

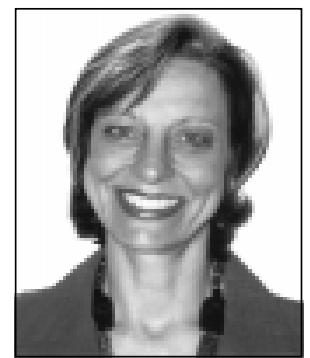

Elsa R. J. Giugliani ${ }^{1}$

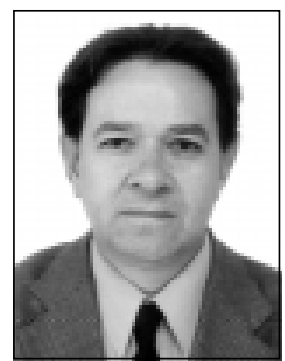

Joel A. Lamounier ${ }^{2}$

\begin{abstract}
As mudanças mais radicais de todos os tempos na alimentação infantil ocorreram entre 1850 e 1970, época em que o leite materno foi gradativamente sendo substituído por leites de outras espécies, cada vez mais modificados na tentativa de "assemelharem-se" ao leite humano. A introdução dos substitutos para o leite humano representa, sem dúvida, o maior experimento in vivo não-controlado ${ }^{1}$. Segundo Moysés Paciornik, nenhuma função humana foi tão agredida, modificada, artificializada quanto a amamentação². Em resposta ao crescente abandono da prática da amamentação e diante das denúncias das conseqüências desastrosas para a saúde infantil da utilização indiscriminada de leites industrializados, especialmente em populações desprivilegiadas, iniciou-se, na década de 70, um movimento que visava à retomada da amamentação como forma preferencial de alimentar a criança pequena ${ }^{3}$. Mas, para isso, seria necessário conscientizar as pessoas sobre os benefícios da amamentação, provando que o leite de outras espécies usado em substituição ao leite que a natureza havia levado milhões de anos aperfeiçoando poderia aumentar o risco de agravo à saúde das crianças. Assim, despertou-se o interesse de cientistas de todo o mundo, que passaram a estudar vários aspectos do leite humano e da amamentação. Como resulta-
\end{abstract}

1. Doutora em Medicina pela Universidade de São Paulo de Ribeirão Preto. Professora de Pediatria, Faculdade de Medicina, Universidade Federal do Rio Grande do Sul. Presidente do Departamento Científico de Aleitamento Materno da Sociedade Brasileira de Pediatria.

2. Doutor em Saúde Pública, Universidade da Califórnia, Los Angeles, EUA. Professor titular, Departamento de Pediatria, Faculdade de Medicina, Universidade Federal de Minas Gerais (UFMG), Belo Horizonte, MG. Professor orientador do Programa de Pós-graduação em Saúde da Criança e do Adolescente da UFMG.

Como citar este artigo: Giugliani ERJ, Lamounier JA. Aleitamento materno: uma contribuição científica para a prática do profissional de saúde. J Pediatr (Rio J). 2004;80(5 Supl):S117-S118. do, foi construído um amplo referencial teórico provando, inequivocamente, a superioridade do leite materno sobre os seus pretensos substitutos. No entanto, apesar de todo o avanço científico e dos esforços de diversos organismos nacionais e internacionais, as taxas de aleitamento materno no Brasil, em especial as de amamentação exclusiva, estão bastante aquém do recomendado. A mediana de amamentação no Brasil é de 10 meses, e de amamentação exclusiva, de apenas 23 dias $^{4}$, contrastando com a recomendação internacional de amamentação exclusiva por 6 meses e complementada por 2 anos ou mais 5 .

Não basta a mulher estar informada das vantagens do aleitamento materno e optar por esta prática. Para levar adiante sua opção, ela precisa estar inserida em um ambiente favorável à amamentação e contar com o apoio de um profissional habilitado a ajudá-la, se necessário. Mas nem sempre o profissional de saúde tem conhecimentos e habilidades suficientes para manejar adequadamente as inúmeras situações que podem servir de obstáculo à amamentação bem-sucedida, em parte porque o aleitamento materno é uma "ciência" relativamente nova, e nem sempre são disponíveis materiais didáticos apropriados sobre o assunto. Um estudo recente mostrou que, em sete livrostexto de pediatria americanos publicados entre 1999 e 2002 (vários deles amplamente utilizados no Brasil), as informações sobre aleitamento materno, quando não omitidas, variavam e, por vezes, eram inacuradas e inconsistentes ${ }^{6}$. Por exemplo, nenhum dos livros recomendava aleitamento materno complementado por no mínimo 1 ano, apenas um recomendava aleitamento materno exclusivo por 6 meses, apenas dois recomendavam o início da amamentação na primeira hora de vida e informavam corretamente as contra-indicações à amamentação e somente três abordavam o manejo do ingurgitamento mamá- 
rio. Este suplemento, portanto, tem como finalidade disponibilizar conhecimentos atualizados sobre aleitamento materno, importantes para o pediatra e outros profissionais que trabalham com mães/bebês.

O primeiro artigo do suplemento busca ampliar a compreensão sobre a natureza híbrida (biologia-cultura) do aleitamento materno. Segundo os seus autores, "a amamentação, além de biologicamente determinada, é socioculturalmente condicionada, tratando-se, portanto, de um ato impregnado de ideologias e determinantes que resultam das condições concretas de vida". Esse entendimento é importante para se compreender o comportamento das mulheres (e de pessoas no seu entorno) frente à amamentação.

Para promover, proteger e apoiar a amamentação com eficiência, o profissional de saúde, além do conhecimento em aleitamento materno e competências clínicas, precisa ter habilidade em se comunicar eficientemente com a nutriz. O artigo "Aconselhamento em amamentação e sua prática" aborda os princípios básicos dessa forma de atuação, que implica acolher e ajudar a mulher a tomar decisões de forma empática, saber ouvir e aprender, desenvolver a confiança e dar apoio.

A partir dos 6 meses, recomenda-se que a criança comece a receber outros alimentos, mas que mantenha a amamentação por 2 anos ou mais. Juntos, o leite materno e os alimentos complementares são fundamentais para o crescimento e o desenvolvimento ótimos da criança. Devido à importância do tópico e em função das mudanças significativas nas atuais recomendações alimentares de crianças amamentadas em relação às recomendações anteriores, este suplemento incluiu um artigo que trata especificamente sobre este tema, apresentando as evidências que embasam essas recomendações.

Os benefícios do aleitamento materno para a criança têm sido bem mais estudados do que os benefícios para a mulher que amamenta. Apesar disso, já são conhecidos alguns efeitos positivos da amamentação para a saúde da mulher. Embora o foco da prática clínica do pediatra seja a criança, ele com freqüência opina sobre assuntos relacionados à saúde da nutriz. Por isso, é muito útil que esse profissional conheça as vantagens que a amamentação traz à mãe, as quais são abordadas no artigo "Benefícios da amamentação para a saúde da mulher".

Além de conhecer bem as vantagens da amamentação para a criança e sua mãe, todo profissional que atende mãe/ bebê, incluindo o pediatra, deve ter conhecimento sobre a prevenção e o manejo dos principais problemas decorrentes da lactação. Ingurgitamento mamário, traumas mamilares, mastites, entre outros, são fonte de sofrimento para a mãe que amamenta, podendo determinar o desmame precoce. No entanto, a maioria dos livros-texto de pediatria não fornece as informações necessárias para o manejo adequado desses problemas. O artigo "Problemas comuns na lactação e seu manejo" aborda aspectos técnicos e práticos necessários para a atuação do profissional frente a esses problemas.

Outro tópico pouco explorado na literatura refere-se às disfunções orais do recém-nascido. Cabe principalmente ao pediatra diagnosticar precocemente esse transtorno e manejá-lo adequadamente. Para isso, é preciso conhecer a fisiolo- gia normal da sucção do recém-nascido e saber avaliar criticamente a técnica da amamentação. O artigo "Manejo clínico das disfunções orais na amamentação" objetiva contribuir para a capacitação do profissional para o manejo clínico adequado das disfunções orais.

Hoje já é consenso a opinião de que o leite materno é particularmente importante na alimentação do recém-nascido prematuro. Apesar disso, em geral é baixa a incidência de êxito na amamentação de prematuros, especialmente em unidades neonatais de risco. O artigo "Aleitamento materno em prematuros: manejo clínico hospitalar" contribui para que o profissional de saúde tenha mais recursos para enfrentar o desafio que é tornar factível a oferta de leite materno aos recém-nascidos pré-termo. Um dos fatores facilitadores da amamentação do prematuro é o Método Mãe Canguru, objeto de um outro artigo deste suplemento. $O$ artigo "Método Mãe Canguru: aplicação no Brasil, evidências científicas e impacto sobre o aleitamento materno" aborda alguns aspectos práticos do método, bem como apresenta as evidências científicas sobre os benefícios dessa prática.

Muitas vezes, o pediatra se vê diante da situação angustiante de ter que contra-indicar a amamentação. Por isso, ele tem que estar seguro quanto à indicação de suspensão da amamentação, mesmo que temporariamente. Os artigos "Recomendações quanto à amamentação na vigência de infecção materna" e "Uso de medicamentos durante a lactação" discutem detalhadamente as situações que podem colocar em risco a criança amamentada, dando subsídios para que o profissional possa avaliar os riscos e os benefícios da amamentação nessas situações.

Por último, incluiu-se um artigo que dá subsídios ao pediatra e outros profissionais para discutir, com embasamento científico, a crença corrente, principalmente entre os odontólogos, de que o aleitamento materno está associado a cáries. O artigo "Aleitamento materno e cárie do lactente e do pré-escolar: uma revisão crítica" analisa os vários estudos epidemiológicos que investigaram uma possível relação entre aleitamento materno e cárie. Com essas informações, o profissional pode posicionar-se e argumentar sobre o tópico.

Acreditamos que este suplemento, além de bastante oportuno, constitui importante contribuição ao movimento de resgate à "cultura e prática da amamentação" em nosso país.

\section{Referências}

1. Hambraeus L. Leites industrializados versus leite humano na alimentação do lactente. Uma apreciação crítica do ponto de vista nutritivo. Clínicas Pediátricas da América do Norte. 1977;24:17-36.

2. Paciornik M. Aprenda a nascer e a viver com os índios. Rio de Janeiro: Ed. Rosa dos Tempos; 1997.

3. Jelliffe DB, Jelliffe EFP. Human milk in the modern world. 2nd ed. Oxford: Oxford University Press; 1978.

4. Ministério da Saúde, Secretaria de Políticas de Saúde, Área de Saúde da Criança. Prevalência de aleitamento materno nas capitais brasileiras e no Distrito Federal. Brasília: Ministério da Saúde; 2001.

5. World Health Organization [site na Internet]. Nutrition and infant feeding. Disponível em: http.//www. who.int/child-adolhealth/nutrition/infant_exclusive.htm. Acessado em: 30/09/ 2004.

6. Philipp BL, Merewood A, Gerendas E, Bauchener H. Breastfeeding information in pediatric textbooks needs improvement. J Hum Lact. $2004 ; 20: 206-10$. 